\title{
MATERIAIS DIDÁTICOS PARA EDUCAÇÃO AMBIENTAL EM UNIDADES DE CONSERVAÇÃO: AS POSSIBILIDADES DE USO DA HIPERMÍDIA
}

\author{
EDUCATIONAL MATERIALS FOR ENVIRONMENTAL EDUCATION IN \\ PROTECTED AREAS: THE POSSIBILITIES OF HYPERMEDIA
}

\author{
MATERIALES EDUCATIVOS PARA LA EDUCACIÓN AMBIENTAL EN ÁREAS \\ PROTEGIDAS: LAS POSIBILIDADES DE USO DE LA HIPERMEDIA
}

\author{
Gelze Serrat Souza Campos Rodrigues - Universidade Federal de Uberlândia - \\ Uberlândia - Minas Gerais - Brasil \\ gelcampos@ig.ufu.br \\ Marlene Teresinha de Muno Colesanti - Universidade Federal de Uberlândia - \\ Uberlândia - Minas Gerais - Brasil \\ mmuno@ufu.br
}

\begin{abstract}
Resumo
0 desenvolvimento e a aplicação das novas tecnologias da informação e comunicação (TICs) têm aberto muitas possibilidades na educação escolar. Na Educação Ambiental, o uso das TICs pode proporcionar a sensibilização, 0 conhecimento virtual de lugares diferenciados e de seus problemas socioambientais, por mais distantes espacialmente que os usuários estejam do ambiente visitado. Considerando essas questões e a partir de uma Educação Ambiental vinculada à pedagogia da complexidade, construiu-se um material didático focado no Parque Municipal Victório Siquierolli, em Uberlândia, Minas Gerais, cujas imagens, textos e sons foram implementados em suporte digital. A hipermídia foi testada e avaliada por alunos, cujos resultados são a base para a reflexão acerca da arquitetura da hipermídia e das potencialidades de seu uso na Educação Ambiental Formal.

Palavras-chave: educação ambiental formal, Parque Victório Siquierolli, hipermídia.
\end{abstract}

\section{Abstract}

The development and application of new information and communication technology (ICT) have opened many possibilities in education. In Environmental Education, the use of ICTs can provide awareness, as well as virtual knowledge of differentiated places and their social and environmental problems, no matter how spatially distant users are from the visited environment. Considering these issues from an Environmental Education outlook linked to pedagogy of complexity, a course material was built focused on Victório Siquierolli Municipal Park in Uberlândia, in the state of Minas Gerais, which images, texts and sounds were implemented in digital form. The hypermedia has been tested and evaluated by students, and the results are the basis for reflection on the hypermedia's architecture and potential for its use in Formal Environmental Education.

Key words: formal environmental education, Victório Siquierolli Park, hypermedia.

\section{Resumen}

El desarrollo y la aplicación de nuevas tecnologías de la información y la comunicación (TICs) han abierto muchas posibilidades en la educación. En Educación Ambiental, el uso de las TICs puede proporcionar la conciencia, el conocimiento virtual de lugares diferenciados y sus problemas sociales y ambientales, aunque los usuarios estén espacialmente distantes. Teniendo en cuenta estas cuestiones y de una Educación Ambiental asociada a la pedagogía de la complejidad, fue construido un material didáctico centrado en el Parque Municipal Victorio Siquierolli, en Uberlândia, en el estado de Minas Gerais, cuyas imágenes, textos y sonidos relacionados con 
el Parque se implementaron en forma digital. La Hipermedia ha sido probada y evaluada por los estudiantes, cuyos resultados son la base para la reflexión sobre la arquitectura de la hipermedia y el potencial para su uso en Educación Ambiental Formal.

Palabras clave: educación ambiental formal, Parque Victorio Siquierolli, hipermedia.

\section{Introdução}

A Política Nacional de Educação Ambiental (PNEA) estabelece que o poder público, em seus diferentes níveis, deve incentivar a sensibilização da sociedade para a importância das Unidades de Conservação (UCs). Paulatinamente, esse processo vem se introduzindo, principalmente, nos Parques Nacionais, Estaduais e Municipais, por serem áreas onde se aliam a função da conservação do sistema ambiental à permissão da visitação pública.

Desse modo, além das funções iniciais de conservação, lazer e contemplação, os Parques têm incorporado funções didáticas, motivando a inserção de Programas de Educação Ambiental em seus Planos de Manejo e em suas atividades com os visitantes. Dependendo da estrutura administrativa e gerencial do Parque, a sensibilização ambiental pode se dar por meio de folhetos informativos, acesso a vídeos e sites, participação em palestras, cursos e visitas monitoradas.

Em relação ao material produzido, seja ele audiovisual e/ou impresso, percebe-se, entretanto, que quando existente, em grande parte, não reflete os objetivos explicitados no Programa Nacional de Educação Ambiental (Brasil, 2005), possuindo, geralmente, uma ótica disciplinar, segmentada e meramente informativa.

Partindo do pressuposto que os materiais utilizados em Educação Ambiental nas UCs devam ir além da simples informação, enfocando temáticas que possam auxiliar no conhecimento de seus aspectos biofísicos e sociais relacionados à UC e seu entorno, e viabilizando a identificação e problematização das questões socioambientais subjacentes, são exploradas, nesse texto, as possibilidades de construção de materiais, em formato digital, que auxiliem na fomentação da Educação Ambiental em Parques. São apresentadas as etapas envolvidas na sua elaboração e considerações sobre as potencialidades de seu uso, tendo como referente espacial o Parque Natural Municipal Victório Siquierolli (Parque Siquierolli), no município de Uberlândia, oeste do Estado de Minas Gerais. 
Educação ambiental e hipermídia

Em Uberlândia, a partir do final dos anos de 1990, seguindo uma tendência nacional de incorporação da dimensão ambiental nas preocupações políticas e de planejamento urbano, a Prefeitura inicia um processo de investimento sistemático na criação de parques. São instituídos, assim, no perímetro urbano, oito parques municipais, dentre eles o Parque Natural Victório Siquierolli, em 2000.

A escolha do Parque Siquierolli como área objeto para a construção da hipermídia levou em consideração o fato dele se constituir um importante fragmento de cerrado, encravado na área urbana de Uberlândia. Além desse fator, o Parque Siquierolli é a única Unidade de Conservação do município, onde atividades de Educação Ambiental, tais como trilhas interpretativas e visitas monitoradas, ocorrem de modo sistematizado, sem contarem, entretanto, com materiais didáticos específicos sobre a área.

Nesse contexto, considerando as possibilidades das novas tecnologias de informação e comunicação (TIC) na divulgação de informações textuais, imagens em geral, músicas, fotografias, filmes e mapas, passou-se à reflexão sobre as possíveis aplicabilidades das novas TICs em materiais com finalidades pedagógicas para a Educação Ambiental em Unidades de Conservação.

As Tecnologias de Informação e Comunicação estão e sempre estiveram presentes ao longo de todo o processo de desenvolvimento humano, podendo ser consideradas como toda configuração comunicativa que utiliza como apoio as tecnologias disponíveis no seu contexto histórico, estando ela relacionada à informática ou não. Contudo, com o aperfeiçoamento dos microprocessadores, sua disseminação e popularização, e possibilidade da digitalização da informação, estabelece-se um ajuste estratégico entre o audiovisual, a informática e as telecomunicações, o que resulta na comunicação virtual e nas denominadas novas tecnologias de comunicação e informação (Silva, 2002). No mesmo sentido, Kensk (2007, p. 25) esclarece que

ao se falar em novas tecnologias, na atualidade, estamos nos referindo, principalmente, aos processos e produtos relacionados com os conhecimentos provenientes da eletrônica, da microeletrônica e das tecnologias. [...] Essas tecnologias caracterizam-se também por terem uma base imaterial, ou seja, não são tecnologias materializa- 
das em máquinas e equipamentos. Seu principal espaço de ação é virtual e sua principal matéria-prima é a informação.

Sob essa perspectiva, a construção de materiais didáticos demanda a reflexão de uma série de questões concernentes à abordagem mais adequada para a construção de saberes por meio da relação entre o sujeito cognoscente e o campo temático das diversas áreas de conhecimento integradas nos conteúdos da mídia proposta; à linguagem a ser utilizada e às técnicas adotadas que possibilitem o uso do computador como uma ferramenta cognitiva.

Em relação à abordagem a ser adotada em materiais didáticos para UCs, partiu-se do pressuposto que além de apresentar as características sociais e biofísicas específicas dos espaços protegidos, o material deve propiciar a reflexão sobre as múltiplas e complexas determinações dos problemas ambientais do lugar onde estão inseridas as Ucs. Do mesmo modo deve estimular formas de ação para combater as suas causas e não apenas os seus efeitos mais aparentes.

Nesse sentido, a apreensão da complexidade ambiental e, portanto, a perspectiva interdisciplinar e a valorização da percepção da comunidade na resolução dos problemas ambientais de diferentes escalas, se consubstanciam como alicerces principais, sobre os quais está assentada a base para a construção dos materiais pretendidos.

Morin (2002) considera a complexidade como uma forma de enxergar o mundo como um sistema complexo, cujas "desordem, incerteza, antinomia fecundam um novo tipo de compreensão e explicação, o do pensamento complexo" (p. 457).

As questões ambientais, portanto, implicam em levar em consideração a complexidade dos sistemas envolvidos, a multiplicidade de seus componentes (físicos, químicos, biológicos, ecológicos, humanos e sociais), a não linearidade dos fenômenos subjacentes, e, sobretudo, a estrutura espacial e as diferentes escalas espaciais e temporais de suas causas e efeitos.

Nessa perspectiva, Leff $(2001,2002)$ afirma que a crise ambiental é uma crise da razão e que os problemas ambientais são sobretudo problemas do conhecimento. Portanto, aprender a complexidade ambiental implica na desconstrução da razão e da racionalidade moderna e na reconstrução do pensamento mediante o saber ambiental e a pedagogia da complexidade ambiental, na qual o grande desafio é preparar "novas 
mentalidades, capazes de compreender as complexas inter-relações entre os processos objetivos e subjetivos que constituem seus mundos de vida, para gerar habilidades inovadoras tendo em vista a construção do inédito" (Leff, 2002, p. 219).

Leff (2001) salienta que o saber ambiental não se constitui em um saber homogêneo. É um saber que vai sendo estabelecido na relação com o objeto e o campo temático das diversas áreas de conhecimento, definindo-se então o ambiental de cada ciência, o que então abre espaço para a interdisciplinaridade, com a formulação de novas teorias, disciplinas e técnicas. Isso pode e deve levar à integração de processos naturais e sociais de diferentes ordens de materialidade e esferas de racionalidade e à formulação de novas estratégias conceituais para a construção de uma nova ordem teórica que questione a atual racionalidade econômica e processos de produção.

Outra questão a ser pontuada é que a lógica da comunicação na comunicação digital é diferente, por exemplo, de um texto impresso. No meio digital o leitor/usuário do material torna-se um construtor ativo do conhecimento acessado (Lévy, 1993), podendo linkar ${ }^{1}$ material visual diverso e mesmo som com imagens, fundindo campos que até então pareciam distintos.

A essa possibilidade de comunicação proporcionada pelo uso de vários meios de informação, como som, imagem animada e imagem estática, dá-se o nome de multimídia. A multimídia normalmente é implementada pela hipermídia, tecnologia não sequencial, organizada pelo link de pedaços de informações, em modo associativo, onde o leitor lê o texto de um nó para outro, podendo não o ler de forma integral, do início ao fim, e utilizando diversas mídias, tais como: textos, mapas, gráficos, vídeos, dentre outros.

Outro ponto a se destacar é o uso de computadores como ferramenta cognitiva, possibilitando o processamento e a compreensão da informação, por meio do estímulo de operações de codificação, armazenamento e comparação das informações (Yildirim, 2005). Nessa perspectiva a técnica utilizada para a construção da hipermídia deve permitir que o computador não apenas apresente a informação, mas também aguce os usuários a acessar, organizar, interpretar e analisar as informações disponibilizadas no programa proposto e em outras plataformas de informação, sejam digitais ou não. 
A construção de uma hipermídia para educação ambiental em unidades de conservação

Ao se construir um material didático, seja ele verbal, visual ou digital, é necessário que primeiramente sejam estabelecidos os objetivos educativos, os quais estão diretamente relacionados à concepção de ensino e aos conteúdos de aprendizagem.

Sob a perspectiva da pedagogia da complexidade ambiental, o desenvolvimento de competências, atitudes e valores são importantes para identificar, problematizar e agir nos sistemas socioambientais complexos, possuindo, os conteúdos de aprendizagem, natureza muito variada, já que dizem respeito a todos os aspectos que permitem "o desenvolvimento das capacidades motoras, afetivas, de relação interpessoal e de inserção social" (Zabala, 1998, p. 30). Nesse sentido, podem ser classificados em três categorias: fatos, conceitos e princípios; procedimentos; e, valores, normas e atitudes (Coll, 2007, p. 163), apesar de sempre se darem de modo integrado.

A primeira categoria se relaciona aos fatos, conceitos, situações, dados e fenômenos concretos (Zabala, 1998, p. 41), como o conceito de unidade de conservação, as características do bioma onde ela está localizada, a identificação de quais são as ameaças antrópicas à sua conservação. Para a compreensão desses conteúdos é necessário que atividades da mídia favoreçam a construção de significados dos novos conceitos por meio do estabelecimento de relações com conhecimentos prévios ou pelas possibilidades de seu uso na construção de novas ideias.

Os conceitos estão estritamente relacionados aos procedimentos, os quais envolvem regras, técnicas, métodos, estratégias, abrangendo ações coordenadas para a realização de um determinado objetivo (Zabala, 1998, p. 43). Podem integrar, no presente caso, uma visita efetiva ao Parque, a observação e o levantamento de problemas ambientais concernentes ao cerrado, a construção de um painel sobre algum tema ambiental, dentre outros procedimentos surgidos a partir do uso da hipermídia.

A dimensão dos valores, normas e atitudes diz respeito aos princípios que orientam o comportamento das pessoas, concretizadas em normas e traduzidas nas atitudes, que são o comportamento de forma consistente e persistente das pessoas frente a alguma situação (Coll, 2007, p. 163). Essa dimensão deve permear toda a hipermídia e levar ao desenvolvimento de atitudes críticas em relação à valorização e à importância das unidades de conservação como espaços especialmente protegidos pela le- 
gislação devido às suas relevantes características biofísicas e, por vezes, socioculturais. É, portanto, uma das dimensões mais importantes, pois deve propiciar ao usuário da hipermídia a identificação clara dos problemas ambientais e a percepção dos conflitos existentes para a conservação desses espaços, bem como das diferentes possibilidades de ação para a solução das questões ambientais que envolvam as UCs e sua relação com os contextos local, regional, nacional e global.

Outra etapa a ser contemplada é a determinação de algumas características do público-alvo que auxiliem na estimativa das suas necessidades de informação, bem como no estabelecimento do conteúdo a ser apresentado, já que grupos socioeconômicos variados, de diferentes faixas etárias, podem ter compromissos e interesses diversos.

No projeto desenvolvido optou-se por alunos dos $6^{\circ}$ ano, considerando-se que a maioria dos escolares que visita o Parque estuda no Ensino Fundamental (81\%, em 2007) e que de acordo com o Parâmetro Curricular de Geografia para o Ensino Fundamental, é a partir dessa fase que as questões socioambientais podem ser trabalhadas de modo mais sistemático, havendo, portanto, a possibilidade do tratamento de diversos conteúdos da atualidade e uma grande abertura para a inserção de projetos interdisciplinares de ensino.

A construção de materiais didáticos em geral pressupõe a realização do levantamento dos dados existentes acerca do tema a ser tratado, o que abrange texto, imagens, relatos. Esse universo é constituído de imagens, impressas ou em formato digital, informações acerca da história da criação da unidade de conservação, sua infraestrutura, características da ossatura da sua paisagem (relevo, vegetação, recursos hídricos, fauna etc.), aspectos relacionados à população que vive dentro da UC ou no seu entorno, manifestações culturais, levantados em pesquisas e referências bibliográficas em geral, bem como em trabalhos de campo e junto à comunidade de seu entorno.

Como geralmente o universo de dados acerca da UC é extenso e no processo de construção de materiais didáticos, em geral, há a preocupação com a introdução progressiva dos temas a serem tratados, surge a necessidade de seleção dos dados a serem apresentados (Soletic, 2001). Após a seleção dos textos e imagens levantadas, executa-se a digitalização do material.

A construção de hipermídias pode ser feita por meio de vários softwares que possibilitem recursos de autoria, edição de imagens com animação, som e interatividade. De acordo com Soares (2004), o primeiro 
passo a ser dado para a criação de uma animação é o desenvolvimento de um fluxograma (Figura1) que indique a estruturação geral a ser criada, organizando hierarquicamente em ordem de importância, as informações, tanto em relação ao menu quanto ao índice interno de cada página a ser acessada. Além disso, a sua concepção deve levar em consideração elementos tais como: cores a serem utilizadas, sons adequados aos objetivos pretendidos e um conteúdo que desperte o interesse. Ele constitui, de fato, um elo entre as diversas informações apresentadas que, quando bem definido, resulta em uma boa navegabilidade.

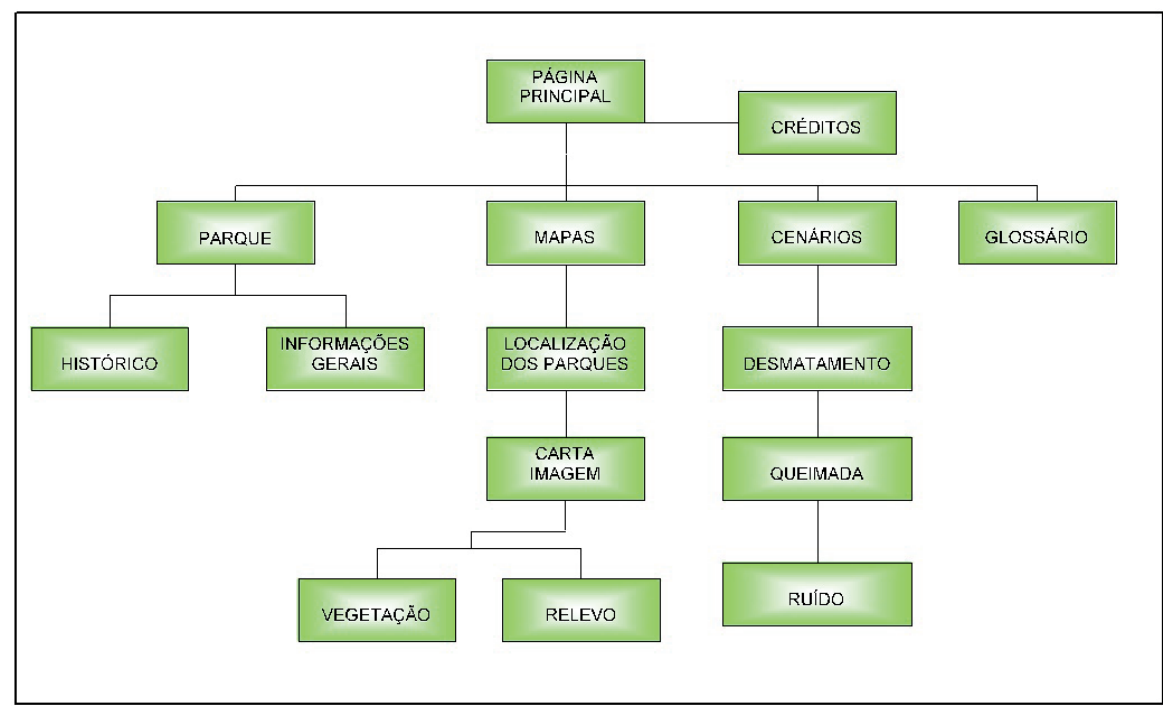

Figura 1 - Fluxograma geral para a criação da hipermídia sobre o Parque Victório Siquierolli. Fonte: Rodrigues (2007, p. 110).

Após a elaboração do fluxograma parte-se para a definição do estilo de arquitetura ou definição do layout (Soares, 2004), o qual possibilita o planejamento visual dos espaços a serem utilizados, a localização dos textos e imagens, a escolha dos tipos, fontes e cores, e faz o esboço sequencial das páginas internas. No planejamento visual, estuda-se também o conteúdo textual a ser apresentado na mídia, tendo-se em mente que, conforme Sancho (2001), a transposição de um texto para um hipertexto só se dá com a modificação desse texto, que deverá ser adaptado ao novo suporte de visualização, sendo que o ideal é que se leia apenas o necessário e relevante. 
Outro ponto importante a ser considerado é a construção da identidade visual da hipermídia, a qual pode se iniciar pela sua metaforização. As metáforas são estimuladores visuais que podem ser apresentados por meio de sons, animações ou imagens estáticas e quando bem definidas propiciam ao usuário uma associação de ideias, reforçando a mensagem que o construtor do projeto quer transmitir (Passarelli, 1993).

Nesse sentido idealizou-se uma metáfora representada por uma árvore endêmica do cerrado - o murici, existente no Parque Siquierolli, cujos frutos compõem o repertório de assuntos acessíveis à pesquisa por parte do usuário. Para o acionamento dos botões (frutos), foi criado um personagem, batizado de Vito, uma analogia ao nome do Parque, o qual reflete a ideia de um ser mutante, figurativo do Curupira (guardião das matas, no folclore brasileiro), com sua cabeleira vermelha e pés virados para trás (Figura 2).

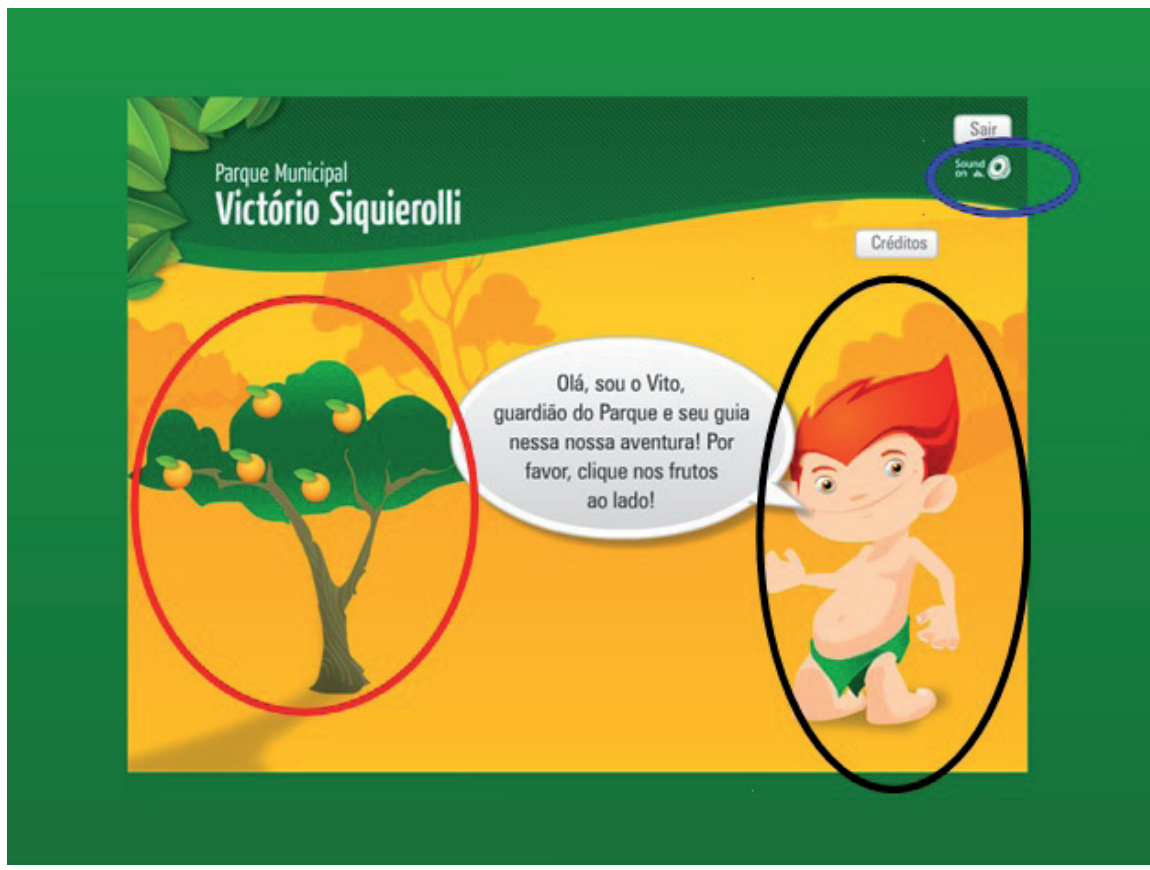

Figura 2 - Metáfora utilizada na mídia, com indicação, em vermelho, do murici e dos respectivos botões-frutos; em preto, Vito; e, em azul, botão de desacionamento da música. 
Como música de fundo foi inserido o maracatu "Segue Embaixadô", música de domínio público, repertoriada nas festas de congada da região de Uberlândia, interpretado pelos grupos mineiros Uákti e Tabinha. Para se evitar a repetição da música de modo contínuo, foi inserido um botão, no lado superior, direito, das cenas, que permite o desligamento ou acionamento da música.

Após a criação dessa metáfora e do fluxograma, deu-se início à modelagem da mídia pelo sistema de navegação, de acordo com os objetivos de aprendizagem expostos anteriormente. Assim, o sistema de navegação passou a ser constituído por cinco botões principais acionados pelos frutos do murici, sendo eles: Parque, Mapas, Cenários, Glossário e Fotos.

No botão Parque o usuário acessa a cena onde são apresentadas informações gerais sobre o Parque (endereço, telefone, horário de visitação e a possibilidade de agendamento de visitas monitoradas para escolas). Com a seleção do fruto-botão relativo a Mapas, o visitante do site tem acesso a um mapa interativo com a localização dos parques municipais de Uberlândia, a uma carta-imagem, mapas de vegetação e de hipsometria do Parque Siquierolli. O botão cenários apresenta cenários evolutivos prováveis das consequências de ações (desmatamento, queimadas e ruídos) dos moradores do entorno e visitantes do parque, selecionadas a partir do levantamento de quais são os principais problemas recorrentes no Parque Siquierolli, na perspectiva dos funcionários e visitantes. O glossário figura como um apêndice dos textos da hipermídia, onde são elucidados alguns dos conceitos mais complexos utilizados. O botão-fruto Fotos dá acesso a uma série de fotos acerca da vegetação e da infraestrutura do Parque.

Após a construção da hipermídia foi realizada a sua avaliação pelo público-alvo, idealizada de forma a contemplar elementos para uma "avaliação exploratória significativa” (Passareli, 1993), possibilitando o processo de reflexão sobre os componentes da mídia, sua interatividade e grau de aceitação, importante para a revisão do projeto desenvolvido.

\section{Resultados e discussão}

A hipermídia foi avaliada por todos os alunos do sexto ano, de duas escolas de Uberlândia, uma pública, a Escola de Educação Básica da Universidade Federal de Uberlândia e outra privada. Após navega- 
rem, por cerca de 20 minutos, os discentes responderam o questionário avaliativo que abordava aspectos relacionados à navegação, à qualidade dos textos, das imagens e do som (Tabela 1), e ao conteúdo. Ao final do questionário, foram também solicitadas sugestões para a melhoria do programa (Tabela 2).

A navegação foi considerada fácil pela maioria dos alunos. Apenas $20 \%$ dos alunos da escola privada e 17\% da escola pública declararam se sentirem perdidos algumas vezes na mídia, o que indica a facilidade da acessibilidade na sua navegação. Tal fato pode ser explicado pelo uso das tecnologias e internet serem lugar comum para a maioria dos alunos. Ao mesmo tempo, o resultado indica que a elaboração do fluxograma geral para a criação do filme (Figura 1) foi feita de forma adequada aos objetivos propostos, permitindo aos usuários a percepção clara dos links entre as informações.

Destaca-se que a criação da metáfora adequada aos objetivos de aprendizagem, possibilita a efetivação do elo afetivo com o interlocutor, auxiliando na construção de conteúdos atitudinais, por meio da elaboração de valores conservacionistas acerca do próprio parque, o que pode ser evidenciado na afirmação de um dos alunos da escola particular: "O Vito é muito fofo e bonitinho e o seu programa também!” (Aluno A), e no registro de uma das sugestões apresentadas por um aluno de escola pública: "Que o Parque Siquerole [sic] se amplie" (Aluno B).

Considerando a arquitetura da hipermídia, os elementos imagem e texto tiveram uma boa aceitação, o que indica a boa legibilidade do projeto, ou seja, a sua boa leitura, alcançada pela escolha das cores de fundo e do texto, do tamanho e estilo da fonte e das imagens. Diferentemente, o elemento música teve um retorno mais negativo do que positivo, com $60 \%$ dos alunos da escola pública e 51\% da escola privada não a apreciando. De acordo com a avaliação geral dos usuários, portanto, a música de fundo utilizada se repetia cansativamente, o que provocava incômodo, ilustrado em uma das avaliações: "A música é chata e repete demais [sic]" (Aluno C). Os dados apresentados nos levam a deduzir que não houve uma composição harmônica entre o som e os demais elementos do projeto-imagens e textos. Além disso, muito provavelmente, o botão de desacionamento da música não teve boa legibilidade, já que os usuários não conseguiram desabilitar a repetição do som. 
Tabela 1 - Dados levantados no questionário avaliativo sobre a arquitetura da hipermídia.

\begin{tabular}{|c|c|c|c|c|}
\hline & \multicolumn{2}{|c|}{ Escola particular } & \multicolumn{2}{|c|}{ Escola pública } \\
\hline & $\begin{array}{c}\text { Número } \\
\text { de alunos }\end{array}$ & $\%$ & $\begin{array}{c}\text { Número } \\
\text { de alunos }\end{array}$ & $\%$ \\
\hline \multicolumn{5}{|l|}{ NAVEGAÇÃO } \\
\hline Fácil & 51 & 80 & 38 & 83 \\
\hline Confusa & 13 & 20 & 8 & 17 \\
\hline \multicolumn{5}{|l|}{ IMAGEM } \\
\hline Gostaram & 55 & 86 & 41 & 86 \\
\hline Não gostaram & 09 & 14 & 05 & 14 \\
\hline \multicolumn{5}{|l|}{ TEXTO } \\
\hline Gostaram & 54 & 85 & 36 & 79 \\
\hline Não gostaram & 10 & 15 & 10 & 21 \\
\hline \multicolumn{5}{|l|}{ MÚSICA } \\
\hline Gostaram & 31 & 49 & 18 & 40 \\
\hline Não gostaram & 33 & 51 & 28 & 60 \\
\hline
\end{tabular}

Fonte: Adaptado pela autora, com base em Rodrigues (2007).

Em relação aos aspectos conceituais, antes dos alunos navegarem pela mídia, foi solicitado que respondessem um pré-questionário a fim de se levantar o seu conhecimento prévio acerca dos Parques Municipais de Uberlândia, suas características e ações que podem afetar a sua qualidade ambiental. As respostas ao questionário revelaram que os alunos tinham conhecimento da existência do Parque Siquierolli, porém não sabiam o que realmente existia nele. Com a navegação na hipermídia, conheceram as propostas de Educação Ambiental oferecidas pela equipe de funcionários do Parque, bem como sua fisionomia ambiental e infraestrutura virtualmente, o que estimulou a curiosidade em conhecê-lo. Alguns alunos da escola privada (14\%), afirmaram, entretanto, categoricamente não se interessarem por Parques Ecológicos.

Em relação à escola pública, a maior parte dos alunos (63\%) já havia ido ao Parque Siquierolli várias vezes, com a escola, familiares e amigos, reiterando os dados sobre os visitantes escolares adquiridos com a administração do Parque, cuja maior porcentagem, é de alunos do Ensino Fundamental e oriundos da escola pública. De fato, o Parque Siquierolli é uma das alternativas de lazer da população do município de Uberlân- 
dia, nos finais de semana, excluída de outras alternativas, como os clubes privados.

A maior parte dos alunos de ambas as escolas (65\% da pública e $36 \%$ da privada) sabiam antes de navegar na hipermídia que a vegetação dominante na região é o cerrado. Após a navegação na hipermídia, esse número subiu para 99\%, nas duas escolas, sendo incluída em cerca de $30 \%$ das respostas as diferentes fitofisionomias existentes no parque, o que demonstra a assimilação do conteúdo apresentado nos mapas do programa por parte dos alunos.

Ao final do questionário $50 \%$ dos alunos da escola pública e $28 \%$ dos alunos da escola privada fizeram sugestões acerca da hipermídia (Tabela 2). A situação de teste nos permitiu inferir que os alunos se interessam pelos materiais didáticos em meio digital, por serem dinâmicos e por poderem selecionar o que querem aprender, contudo consideram importante a inserção de jogos educativos. Isso reforça o importante papel de atividades lúdicas no processo ensino-aprendizagem, principalmente, em projetos de hipermídia, onde há um grande potencial na constituição da interação e atração das crianças e jovens com os temas apresentados.

Tabela 2 - Sugestões apresentadas pelos discentes para a melhoria da hipermídia.

\begin{tabular}{|l|c|c|c|c|}
\hline \multirow{2}{*}{\multicolumn{1}{|c|}{ Sugestões }} & \multicolumn{2}{c|}{ Escola Pública } & \multicolumn{2}{c|}{ Escola Particular } \\
\cline { 2 - 5 } & Total & $\%$ & Total & $\%$ \\
\hline Inserção de jogos & 14 & 60 & 5 & 27 \\
\hline Trocar a música & 6 & 26 & 4 & 22 \\
\hline Inserção de som nas falas do Vito & 3 & 13 & 3 & 16 \\
\hline $\begin{array}{l}\text { Deveria ser mais longo, ter mais } \\
\text { tópicos }\end{array}$ & 2 & 8 & 2 & 11 \\
\hline Trocar o nome do Vito para Curupira & 1 & 4 & - & - \\
\hline Inclusão de formulários ${ }^{2}$ & 1 & 4 & - & - \\
\hline Inclusão de mais fotos & 1 & 4 & - & - \\
\hline Inserção de mais cenários & 1 & 4 & 1 & 5 \\
\hline Inserção de charadas & - & - & 1 & 5 \\
\hline $\begin{array}{l}\text { Acrescentar uma amiga índia que } \\
\text { ajudasse o Vito }\end{array}$ & - & - & 1 & 5 \\
\hline $\begin{array}{l}\text { O Vito deveria ter um animal de } \\
\text { estimação selvagem }\end{array}$ & - & - & 1 & 5 \\
\hline
\end{tabular}




\section{Considerações finais}

O amplo uso das tecnologias digitais, hodiernamente, tem implicado em mudanças de atitudes, valores e comportamentos, demandando novas metodologias educacionais mais sintonizadas com os interesses das novas gerações, já que o processo educacional é um ato comunicativo e se não há sintonia não há comunicação.

Considerando essa perspectiva, procurou-se apresentar alguns aspectos relacionados à interação entre EA em UCs e hipermídia, focando o público pré-adolescente, já que o desenvolvimento da Educação Ambiental em espaços especialmente protegidos também necessita de materiais didáticos ajustados ao tempo tecnológico atual e às demandas de seus visitantes.

Partimos do pressuposto que os materiais didáticos são ferramentas úteis para a construção de saberes ambientais, bem como na consolidação das informações ambientais sobre as unidades de conservação. Contudo, a efetividade da aprendizagem não está relacionada com a inserção pura e simples da hipermídia como uma ferramenta cognitiva, mas sim com a forma como ela se integra a um processo de reflexão sobre o conteúdo apresentado e os interesses do usuário, por meio da ação dos educadores ambientais dos Parques. Por outro lado, se acessada previamente, antes da visitação, em outros espaços, como a escola, pode constituir-se em elemento estimulador à visitação e facilitador de um conhecimento mais consistente sobre a UC.

Consideramos, ainda, que apesar de uma série de documentos, nacionais e internacionais, definirem os conceitos, características e princípios necessários para o estabelecimento da Educação Ambiental nas UCs, o seu desenvolvimento nesses espaços ainda padece de uma orientação mais definitiva.

Sem dúvida a questão ambiental é um campo interdisciplinar, pois nela se entrecruzam o conhecimento técnico-científico, os valores de grupos culturais distintos, o estético-cultural, a natureza e a não natureza, regidos por razões diferenciadas, porém não dicotômicas. Faz, portanto, parte da lógica da complexidade, pois se inscreve na interface da sociedade com a natureza e daí a grande dificuldade em lidar com ela, já que nos marcos do pensamento herdado no mundo ocidental, natureza e sociedade são termos excludentes. E essa mudança da forma de se pensar é apenas um dos primeiros passos para a efetivação de uma Educa- 
ção que se quer denominar como ambiental e vinculada à pedagogia da complexidade.

Sem dúvida há um imenso caminho a ser trilhado no tocante às pesquisas sobre os efeitos cognitivos do uso da hipermídia na educação em geral, em como o uso desses meios afetam a percepção e a representação espacial do ambiente e o desenvolvimento das relações temporoespaciais dos usuários, sobretudo no atual estágio de desenvolvimento do processo tecnológico, onde a comunicação multimídia se expande por meio do uso das tecnologias móveis.

\section{Notas}

1. Devido ao uso corrente da língua inglesa no jargão da informática, foi dada preferência à continuidade do seu uso, acompanhado das devidas explicações. Linkar: unir ou ligar dois softwares ou hardwares (Dicionário Prático de Informática, 1993, p. 188).

2. É o elemento dentro do site que permite ao visitante se comunicar com o seu desenvolvedor ou uma comunidade.

\section{Referências}

BRASIL. Política Nacional de Educação Ambiental. Brasília: Senado Federal, 1999. . Programa Nacional de Educação Ambiental. 3. ed. Brasília: Ministério do Meio Ambiente, 2005.

COLL, C. Psicologia e currículo. São Paulo: Ática, 2007.

COLliN, S. M. H. Michaelis: dicionário prático de informática. São Paulo: Melhoramentos, 1993.

LEFF, E. Saber ambiental. Petrópolis, RJ: Vozes, 2001.

. Epistemologia ambiental. São Paulo: Cortez, 2002.

LÉVY, P. As tecnologias da inteligência. São Paulo: Ed. 34, 1993.

MORIN, E. A religação dos saberes: o desafio do século XXI. Rio de Janeiro: Bertrand Brasil, 2002.

RODRIGUES, G. S. S. C. Educação ambiental e hipermídia: a construção de um material didático para o Parque Municipal Victório Siquierolli, Uberlândia, MG. Tese (Doutorado em Geografia e Gestão Territorial) - IG-UFU, Uberlândia, 2007.

PASSARELLI, B. Hipermídia na aprendizagem: construção de um protótipo interativo: a escravidão no Brasil. Tese (Doutorado em Ciências da Comunicação) - Departamento de Cinema, Rádio e Televisão da Escola de Comunicações e Artes, Universidade de São Paulo, São Paulo, 1993. 
SANCHO, J. M. (Org.). Para uma tecnologia educacional. Porto Alegre: Artmed, 2001.

SILVA, B. D. A inserção das tecnologias de informação e comunicação. Repercussões e exigências na profissionalidade docente. In: MOREIRA, A. F. B.; MACEDO, E. F. de (Orgs.). Currículo, práticas pedagógicas e identidades. Portugal: Porto Editora, 2002. p. 65-91.

SOARES, F. B. Ideias criativas em Flash MX. Rio de Janeiro: Ciência Moderna, 2004.

SOLETIC, A. A produção de materiais escritos nos programas de educação a distância: problemas e desafios. In: LITWIN, E. Educação a distância: temas para o debate de uma nova agenda educativa. Porto Alegre: Artmed, 2001. p. 73-92.

YILDIRIM, Z. Hypermedia as a cognitive tool: student teachers' experiences in learning by doing. Nova Zelândia, 2005. Disponível em: <http://www.ifets.info/ journals/8-2/10.pdf>. Acesso em: 2 out. 2005.

ZABALA, A. A prática educativa: como ensinar. Porto Alegre: Artmed, 1998.

Gelze Serrat Souza Campos Rodrigues - Possui Graduação em Geografia pela Universidade de São Paulo. Mestrado em Geografia pela mesma Universidade e Doutorado em Geografia pela Universidade Federal de Uberlândia. Atualmente é professora no Instituto de Geografia da Universidade Federal de Uberlândia.

Marlene Teresinha de Muno Colesanti - Possui Graduação em Geografia pela Faculdade de Filosofia Ciências e Letras de Catanduva. Mestrado e Doutorado em Geografia pela Universidade Estadual Paulista Júlio de Mesquita Filho. Atualmente é professora no Instituto de Geografia da Universidade Federal de Uberlândia.

Recebido para publicação em 10 de abril 2015

Aceito para publicação em 2 de junho de 2015 